\title{
Polylactide composites with calcium-containing fillers
}

\author{
Andrii Masyuk, Diana Katruk, Volodymyr Levytskyi \\ 1. Department of Chemical Technology of Plastics, Lviv Polytechnic National University, UKRAINE, Lviv, S. \\ Bandera Street 12, E-mail: masyukas@gmail.com
}

\begin{abstract}
Polylactide composite materials with calcium-containing fillers, in particular calcium orthophosphate and calcium hydroorthophosphate, have been developed and investigated. A change in the morphology of the obtained materials was revealed, in particular, an increase in the degree of crystallinity of filled and heat-treated polylactide materials was noted. There is a change in surface hardness and thermomechanical characteristics of polylactide materials due to the action of calciumcontaining fillers.
\end{abstract}

Keywords- polylactide, calcium phosphates, composite, surface hardness, crystallinity

\section{Introduction}

Much of the currently used plastic materials are derived from polymers based on petroleum raw materials, because these materials have high barrier and physico-mechanical properties. In addition, their significant advantages are low cost of production and high productivity of the processes of their synthesis and manufacture of products based on them. In addition, the limitations of the widespread use of these materials are due to their low biodegradability and depletion of raw materials. Therefore, more and more attention is paid to the use of biodegradable polymeric materials from renewable raw materials that are capable of rapid decomposition in the environment under the influence of external factors (moisture, heat, microorganisms, ultraviolet radiation, etc.). The most promising and most widely used of these polymers is polylactide (PLA) - a biocompatible biodegradable thermoplastic polymeric material, which has good strength and rigidity and high thermophysical properties [1].

Among the methods of targeted influence on the morphology and properties of polymers, including polylactide, the most promising is the development of composite materials based on them with fillers of different nature (in particular, hydroxyapatite, calcium phosphate, talc, silicates, etc.).

\section{Experimental}

Ingeo $2500 \mathrm{HP}$ polylactide (NatureWorks, USA) and fine fillers of calcium orthophosphate and calcium hydroorthophosphate were used in the work to obtain polymer composite materials.

Polylactide materials were obtained by mixing the bulk components in a drum mixer for 10-15 minutes. The mixture was then homogenized by stirring in a viscous state on a Cellier laboratory extruder, followed by extrusion and cooling of the extrudate. Samples for testing were obtained from crushed on a crusher gear-type extrudates by injection molding on a thermoplastic Krauss Maffei KM-125 C1-520. The filler content was 2\% by weight [2].

Additional heat treatment of materials was carried out in a heat cabinet for $120{ }^{\circ} \mathrm{C}$ for 3,5 , 10 minutes. The samples were heat-treated for $10 \mathrm{~min}$, additionally heat-treated $5 \mathrm{~min}$ after cooling

\section{Results and discussion}

X-ray examinations show that pure PLA crystallites are typical orthorhombic or pseudoorthorhombic crystals with lattice parameters: $a=10.66 \AA, b=6.16 \AA, c=28.88 \AA$. and the type of crystal structure of the PLA does not change even during the introduction of the filler. In addition, the X-ray diffraction patterns of the filled materials show a decrease in the width of the 
main reflex (at $2 \theta-16.5^{\circ}$ ) by half its height. This change is interpreted as an increase in the size of the crystallites, which is proportional to the decrease in the width of the peak.

It was found that the highest value of the degree of crystallinity $(46 \%)$ is characteristic of the heat-treated sample of polylatide material, and the lowest, respectively, for the original unfilled polylatide (22\%). In this case, the introduction of the filler contributes to some increase in the degree of crystallinity by $4-6 \%$, which is due that the filler particles act as centers of nucleation of polylactide crystallites.

It was investigated that the thermomechanical curves of polylactide composites, regardless of the nature of the fine filler, are characteristic of polymers with a partially crystalline structure. It is established that the transition to the viscous state of composites based on PLA occurs at 190$193^{\circ} \mathrm{C}$. These temperatures are significantly lower than the temperatures of thermo-oxidative destruction of PLA macromolecules $\left(280-340{ }^{\circ} \mathrm{C}\right)$, which allows PLA composites to be processed by injection molding, extrusion, 3D printing, etc.

It was found that the introduction of calcium-containing fillers slightly increases the Vicat softening point of developed materials. At the same time, additional heat treatment significantly affects the value of Vicat softening point, in particular, there is an increase by $40-50{ }^{\circ} \mathrm{C}$. Such changes are obviously associated with an increase in the degree of crystallinity of polylactide materials and the enhancing effect of filler particles.

Also, additional heat treatment contributes to a significant increase in the surface hardness of polylactide materials, regardless of the nature of the filler. The highest values of hardness are marked by heat-treated filled polylactide materials for $10 \mathrm{~min}$ for $120{ }^{\circ} \mathrm{C}$ (298 MPa). In this case, there is a similar effect of the filler on the value of surface hardness, regardless of the nature of the acid residue of the calcium-containing filler. It was found that composites with $\mathrm{Ca}_{3}\left(\mathrm{PO}_{4}\right)_{2}$ have slightly higher values of surface hardness than composites filled with $\mathrm{CaHPO}_{4}$.

\section{Conclusion}

Polylactide composite materials filled with calcium orthophosphate and calcium hydroorthophosphate were obtained. On the basis of the carried-out X-ray diffraction analysis the growth of degree of crystallinity of the developed materials and change of the sizes of crystallites, in particular, the greatest degree of crystallinity is characteristic of heat-treated polylactide material - $46 \%$ is established.

The change of surface hardness and thermomechanical characteristics of polylactide materials, in particular, the maximum values of Vicat softening point is $122-123^{\circ} \mathrm{C}$ and surface hardness of 295-298 MPa are observed for heat-treated samples with calcium phosphate content of $2 \%$ by weight.

\section{References}

[1] Maria Laura, Di Lorenzo, René Androsch (2018). Industrial Applications of Poly(lactic acid). Cham:Springer. https://www.springer.com/gp/book/9783319754581

[2] Masyuk, A. S., Kysil, Kh. V., Katruk, D. S., Skorokhoda, V. I., Bilyi, L. M. \& Humenetskyi T. V. (2020) Elastoplastic Properties of Polylactide Composites with Finely Divided Fillers. Materials Science, 55, 4, 555-562. https://doi.org/10.1007/s11003-02000432-y 